Z. klin. Chem. u. klin. Biochem.

8. Jg., S. $621-625$, November 1970

\title{
K-Transport und Stoffwechsel von Mg-arm gewachsenen Yoshida-Ascitestumorzellen
}

\author{
Von Th. GüNther und R. Averdunk \\ Aus dem Physiologisch-chemischen Institut und dem Institut für Klinische Chemie und Klinische Biochemie \\ der Freien Universität Berlin
}

(Eingegangen am 30. Juli 1970)

An Mg-arm gewachsenen Yoshida-Ascitestumor-Zellen waren Atmung, Glykolyse, ATP-Gehalt und Aktivität der Na-K-aktivierbaren Membran-ATPase unverändert.

Die intrazelluläre K-Konzentration hat infolge eines erhöhten K-Efflux abgenommen. Intrazelluläres $\mathrm{K}$ war im Verhältnis $2: 1$ durch $\mathrm{Na}$ ersetzt.

Die im Mg-Mangel reduzierte Einbaurate markierter Bausteine in RNA, DNA und Protein wird auf die veränderte intrazelluläre K- und Na-Konzentration zurückgeführt.

Die Ursachen für die Änderung der intrazellulären Alkaliionenkonzentration werden diskutiert.

\section{The transport of potassium and the metabolism in Mg-deficient Yoshida-Ascites tumour cells}

In Mg-deficient Yoshida-Ascites tumour cells, tespiration, glycolysis, ATP concentration and the activity of the Na-K-activated membrane ATPase were unchanged.

There was a decreased concentration of intracellular $\mathrm{K}$, caused by an increased $\mathrm{K}$ efflux. Intracellular $\mathrm{K}$ was replaced by $\mathrm{Na}$, 'giving a ratio of $2: 1$.

The reduced tate of synthesis of RNA, DNA and protein in Mg-deficiency is due to the changed intracellular K-Na-concentration. The reasons for the change of intracellular alkali ion concentration are discussed.

Bei $\mathrm{Mg}$-arm gewachsenen Bakterien, die einen stark verminderten $\mathrm{Mg}$-Gehalt aufwiesen, war u. a. das Enzymmuster verändert (1) und die intrazelluläre K-Konzentration (2) herabgesetzt. Bei jungen, wachsenden Ratten wurde nach $\mathrm{Mg}$-armer Ernährung ebenfalls eine Änderung im Enzymmuster und eine geringe Abnahme der intrazellulären K-Konzentration $(3,4)$ festgestellt, obgleich der $\mathrm{Mg}$-Gehalt in einigen Organen nur wenig oder gar nicht erniedrigt war. An Rattenembryonen, deren Mütter $\mathrm{Mg}$-arm ernährt wurden, war der $\mathrm{Mg}$ - und $\mathrm{K}-\mathrm{Gehalt}$ wesentlich stärker herabgesetzt (5). Die Abnahme der intrazellulären K-Konzentration im Mg-Mangel verhält sich also proportional der Wachstumsgeschwindigkeit. Auf welche Weise die Abnahme der K-Konzentration im $\mathrm{Mg}$-Mangel zustande kommt, ist nicht bekannt. Da für den aktiven K-Transport Energie bzw. ATP und bei eukaryotischen. Zellen eine $\mathrm{Na}-\mathrm{K}$-aktivierbare $\mathrm{Mg}$ abhängige ATPase erforderlich ist, untersuchten wir diese Beziehungen an schnell wachsenden YoshidaZellen, die in Mg-armem Medium gezüchtet worden waren.

\section{Methoden}

Yoshida-Ascitestumorzellen wurden in Suspension (6) in EagleMedium (7), dem 10\% (v/v) Mg-frei dialysiertes Kälberserum und $5 \%(v / v)$ fötales Kälberserum (Rehartuin F) zugegeben wurde, gezüchtet. Bei den $\mathrm{Mg}-\mathrm{Mangel}-Z$ ellen wurde das $\mathrm{MgCl}_{2}$ des Eagle-Mediums durch eine äquivalente Menge $\mathrm{NaCl}$ ersetzt. Die Mg-Konzentration im Mg-armen Medium betrug 0,18 mMol/l, im normalen Medium 1,0 mMol $/ l$. Es wurden $1,6-2,4 \cdot 10^{6}$ Zellen in $20 \mathrm{ml}$ Kulturmedium in Luft $/ \mathrm{CO}_{2}(95: 5, \mathrm{v} / \mathrm{v})$ angesetzt. Nach jeweils 3 Tagen Inkubation bei $37^{\circ}$ wurden die Zellen abzentrifugiert und in frischem Medium weiterinkubiert. Die Menge des Wachstumsmediums wurde dabci der Zellzahl proportional erhöht.

Zur Bestimmung der abgestorbenen Zellen haben wir $0,2 \mathrm{~m} l$ Zellsuspension mit $0,1 \mathrm{ml}$ einer frisch bereiteten TrypanblauLösung $(1 \mathrm{~g} / 100 \mathrm{ml} 0,15 \mathrm{M} \mathrm{NaCl})$ versetzt und den Prozentsatz der blau gefärbten Zellen nach $30 \mathrm{Min}$. im Mikroskop ausgezählt (8). Die Zellkonzentrationen haben wir mit dem Coulter Counter Mod. B ermittelt.

Zur Bestimmung des Na-K-Gehaltes wurden die Zellen durch $10 \mathrm{Min}$. Zentrifugieren bei $70 \mathrm{~g}$ vom Kulturmedium abgetrennt, mit $0,1 \mathrm{M} \mathrm{MgCl}$ gewaschen, wozu $5 \mathrm{Min}$. bei $25 \mathrm{~g}$ und $3 \mathrm{Min}$. bei $1700 \mathrm{~g}$ zentrifugiert wurde, und gefriergetrocknet. Nach Veraschen mit konz. $\mathrm{HNO}_{3}$ wurde der $\mathrm{Na}$ - und $\mathrm{K}$-Gehalt flammenphotometrisch bestimmt.

Der $\mathrm{Mg}$ - und $\mathrm{Ca}-\mathrm{Gehalt}$ wurde nach Waschen in $0,15 \mathrm{M} \mathrm{NaCl}$ und Enteiweißen mit 10proz. Trichloressigsäure bestimmt. Mg wurde nach Zugabe von $0,1 \% \mathrm{La}$ (als $\mathrm{LaCl}_{3}$ ) im Atomabsorptionsspektrophotometer gemessen, $\mathrm{Ca}$ durch photometrische Titration mit EDTA (9) ermittelt.

Der Ansatz zur Bestimmung der ATPase-Aktivität der Zellmembranen enthiclt in $1 \mathrm{ml} 0,1 \mathrm{M}$ Imidazolpuffer $\mathrm{pH} 7,5$ :

$5 \mu \mathrm{Mol} \mathrm{ATP}, 5 \mu \mathrm{Mol} \mathrm{MgCl}_{2}, 100 \mu \mathrm{Mol} \mathrm{NaCl}, 20 \mu \mathrm{Mol} \mathrm{KCl}$ und etwa $10 \mu \mathrm{g}$ Membranpräparation. Die $\mathrm{Na}-\mathrm{K}$-unabhängige $\mathrm{Mg}$ ATPase wurde in Gegenwart von 0,1 mm Ouabain getestet. Für die Membranpräparation wurden die Zellen einmal mit $0,15 \mathrm{M} \mathrm{NaCl}$, $5 \mathrm{~mm}$ Tris pH 7,4, 0,2 $\mathrm{mm} \mathrm{Mg} \mathrm{SO}$ gewaschen und in der gleichen Lösung in 2proz. Zellsuspension im Ribi-Zellfraktionator mit 200000 pounds/square inch bei $2-8^{\circ}$ aufgebrochen. Zum Zellhomogenat haben wir $1 \mathrm{~mm}$ EDTA zugegeben und bei $100000 \mathrm{~g}$ zentrifugiert. Der Uberstand wurde 1 Std. bei $1000000 \mathrm{~g}$ zentrifugiert, cinmal mit $0,25 \mathrm{M}$ Rohrzucker $-1 \mathrm{~mm}$ Imidazol $\mathrm{pH}$ 7,5-1 mar EDTA und anschließend zweimal in $1 \mathrm{~mm}$ Imidazol $1 \mathrm{~mm}$ EDTA gewaschen.

Die ATPase-Reaktion wurde mit ATP gestartet, 20 bzw. 40 Min. bei $30^{\circ}$ unter Schütteln inkubiert und mit $0,5 \mathrm{~m} / 10$ proz. Trichloressigsäure gestoppt. $\ln 0,5 \mathrm{ml}$ des Trichloressigsäure-Uberstandes wurde $P_{1}$ nach $F_{t s k e}$ und Subbarow (10), im TrichloressigsäureSediment das Protein nach Lowry u. Mitarb. (11) crmittelt. 
Der Sauerstoffverbrauch der Zellen wurde in Eagle-Medium mit $5^{\circ}$ ' fötalem Kälberscrum direkt manometrisch gemessen. Glucosc bestimmten wir mit Glucoseoxydase, ATP und Lactat in UV-Test ( $\mathrm{Fa}$. Bochringer, Mannheim).

Der Einbau von ${ }^{3} \mathrm{H}-\mathrm{Thymidin}$ in DNA, ${ }^{3} \mathrm{H}$-Uridin in RNA und von ${ }^{11} \mathrm{C}$-Leucin in Protein wurde im gleichen Ansatz von $2,5 \mathrm{ml}$ während zweistündiger Inkubation unter $Z$ ugabe von $0,1 \mu \mathrm{C}{ }^{3} \mathrm{H}$ Thymidin, $0,1 \mu \mathrm{C}{ }^{3} \mathrm{H}$-Uridin und $0,04 \mu \mathrm{C}{ }^{14} \mathrm{C}$-Leucin gemessen (12). Nach Stoppen der Reaktion mit 10proz. Trichloressigsäure wurde dic RNA durch $20 \mathrm{Min}$. Hydrolyse mit $0,1 \mathrm{M} \mathrm{NaOH}$ bei $70^{\circ}$ abgetrennt. Anschließend fällten wir Protein und DNA mit kalter 10N Trichloressigsäure. Die DNA wurde $15 \mathrm{Min}$. in 10 proz. Trichloressigsäure bei $90^{\circ}$ hydrolysiert und mit Äther ausgeschüttelt. Das verbleibende Protein wurde in $0,1 \mathrm{~N} \mathrm{NaOH}$ gelöst. In aliquoten Teilen der einzelnen Fraktionen wurde die ${ }^{3} \mathrm{H}-\mathrm{bzw}$. ${ }^{14} \mathrm{C}$-A ktivität im Tri-Carb-Spektrometer gemessen.

Zur Bestimmung der ${ }^{42} \mathrm{~K}$-Aufnahme wurden beide Zellarten in Eagle-Medium mit $10 \%$ Kälberserum inkubiert. Die Zellkonzentration betrug $6 \cdot 10^{6}$ Zellen pro $\mathrm{ml}$. Die Aufnahme wurde durch Zugabe von $30 \mu \mathrm{C}{ }^{42} \mathrm{KCl} / 10 \mathrm{ml}$ (spezifische Aktivität: $5 \cdot \mathrm{mC}$ / $200 \mathrm{mg} \mathrm{KCl}$ ) gestartet. $\mathrm{Zu}$ den angegebenen Zeiten wurde $1 \mathrm{ml}$ der Zellsuspension durch Membranfilter (Porenweite $2,4 \mu \mathrm{m}$, Fa. Sartorius) gesaugt und einmal mit $5 \mathrm{ml}$ kalter $0,15 \mathrm{M} \mathrm{NaCl}$ gewaschen. Filter und Zellen wurden in $\mathrm{NaOH}$ unter Erwärmen gelöst.

Zur Bestimmung der ${ }^{42} \mathrm{~K}$-Abgabe wurden die Zellen 2 Stdn. mit $30 \mu \mathrm{C}{ }^{42} \mathrm{~K} / 10 \mathrm{~m} l$ Suspension in Eagle-Medium vorinkubiert, mit $0,15 \mathrm{M} \mathrm{NaCl}$ genraschen und in Eagle-Medium reinkubiert. $\mathrm{Zu}$ verschiedenen Zeiten wurde $1 \mathrm{~m} l$ durch Membranfilter abgesaugt. In aliquoten Teilen wurde die Aktivität im $\gamma$-Spektrometer (Perkin-Elmer) gemessen.

\section{Ergebnisse \\ Wachstum}

Die Zellen der Normalkultur wuchsen bis zum 4. Tag logarithmisch. Ihre Generationszeit betrug etwa 24 Stdn. Zwischen dem 4. und 8. Tag nahm die Zellzahl weiter $\mathrm{zu}$, die Generationszeit ist aber wesentlich länger.

Die Mg-Mangel-Kulturen zeigten nur während der ersten $24 \mathrm{Stdn}$. logarithmisches Wachstum (Abb. 1). Nach 8 Tagen ist die Zellzahl in der Normalkultur dreimal so hoch wie in der Mg-Mangel-Kultur. Die Wachstumskurven (Abb. 1) sind gut reproduzierbar, wenn die Zellkonzentration bei $10^{5}$ Zellen $/ \mathrm{ml}$ liegt. Bei höheren Zellkonzentrationen nimmt die Generationszeit schon nach $24 \mathrm{Stdn}$. zu.

Bei längerer Wachstumsdauer hört die Zellvermehrung in der Mg-armen Kultur nach etwa 12 Tagen auf und die Zellen degenerieren. Die Normalkultur dagegen wächst weiter, wenn auch mit langsamerer Geschwindigkeit.

Die Anzahl der abgestorbenen (Trypanblau-färbbaren) Zellen war unter unseren Versuchsbedingungen in

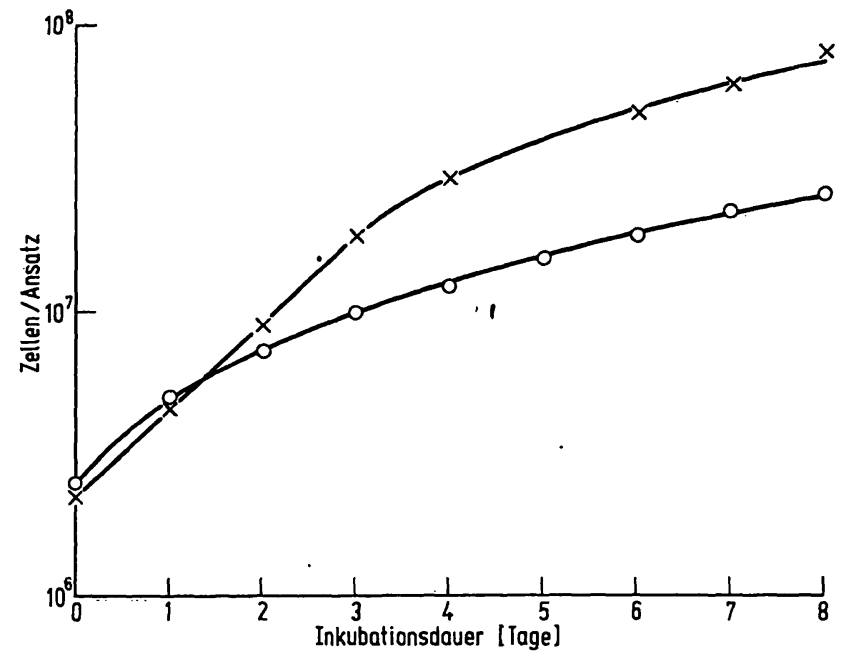

Abb. 1

Wachstumskurve von Yoshida-Zellen in normalem ( $x$ ) und $\mathrm{Mg}$ armem (o) Eagle-Medium mit $10 \%$ Mg-frei dialysiertem Kälberserum und $5 \%$ foetalem Kälberserum. Volumen des Ansatzes zu Versuchs. beginn: $20 \mathrm{ml}$

Tab. 1

Prozentsatz Trypanblau-färbbarer Zellen nach verschieden langem Wachsen in normalem und Mg-armem Medium $(\bar{x} \pm s$ (Standardabweichung)

Trypanblau-färbbare Zellen [\%]

Tag Normalmedium Mg ${ }^{++-a r m e}$

\begin{tabular}{rrr}
\hline & $2,0 \pm 0,2$ & $2,0 \pm 0,2$ \\
2 & $2,0 \pm 0,2$ & $2,3 \pm 0,2$ \\
3 & $2,7 \pm 0,5$ & $3,1 \pm 0,6$ \\
4 & $2,8 \pm 0,5$ & $3,9 \pm 0,7$ \\
5 & $4,1 \pm 0,6$ & $5,3 \pm 0,9$ \\
6 & $7,3 \pm 1,6$ & $9,4 \pm 1,1$ \\
7 & $10,1 \pm 2,3$ & $12,7 \pm 1,3$ \\
8 & $13,5 \pm 3,1$ & $16,4 \pm 3,5$ \\
\hline
\end{tabular}

beiden Kulturen gleich, sie stieg von $2 \%$ auf 13 bis $16 \%$ (Tab. 1).

\section{Stoffwechsel}

Während der 8tägigen Versuchszeit traten in der Atmung, im aeroben Glucoseverbrauch und in der aeroben Lactatbildung bei den Kontroll- und $\mathrm{Mg}$ Mangel-Zellen keine wesentlichen Unterschiede auf (Tab. 2). Damit übereinstimmend war auch der ATPGehalt am 8. Tag des Versuchs in beiden Kulturen mit $0,234 \mu \mathrm{Mol}$ ATP $/ 10^{9}$ Zellen gleich. Die Zellzahl als Bezugssystem ergibt die gleichen Ergebnisse wie andere Bezugssysteme, denn RNA-, DNA- und ProteinGehalt pro Zelle zeigten bei normalen und Mg-MangelZellen keinen signifikanten Unterschied.

Tab. 2

Atmung, aerober Glucoseverbrauch und aerobe Lactatbildung von Yoshida-Zellen nach verschieden langem Wachsen in normalem oder Mg-

\begin{tabular}{|c|c|c|c|c|c|c|}
\hline \multirow[t]{2}{*}{ Tag } & \multicolumn{2}{|c|}{$\mathrm{O}_{2}$-Verbrauch $[\mu \mathrm{l} / \mathrm{mg} \mathrm{TG} \cdot \mathrm{Std}]}$. & \multicolumn{2}{|c|}{ Glucoseverbrauch $\left[\mu \mathrm{Mol} / 10^{\prime}\right.$ Zellen $\cdot$ Std. $]$} & \multicolumn{2}{|c|}{ Lactatbildung $\left[\mu \mathrm{Mol} / 10^{\prime} \mathrm{Z}\right.$ Zllen $\cdot$ Std.] } \\
\hline & Normalzellen & Mg-arme Zellen & Normalzellen & Mg-arme Zellen & Normalzellen & Mg-arme Zellen \\
\hline 1 & $7,62 \pm 0,31$ & $7,57 \pm 0,34$ & $2,40 \pm 0,18$ & $2,53 \pm 0,17$ & $1,14 \pm 0,09$ & $1,24 \pm 0,08$ \\
\hline 2 & $7,88 \pm 0,30$ & $7,71 \pm 0,36$ & $2,36 \pm 0,19$ & $2,61 \pm 0,23$ & $1,03 \pm 0,08$ & $1,13 \pm 0,10$ \\
\hline 3 & $7,84 \pm 0,33$ & $7,67 \pm 0,31$ & $2,44 \pm 0,21$ & $2,53 \pm 0,19$ & $0,97 \pm 0,09$ & $1,13 \pm 0,08$ \\
\hline 4 & $7,56 \pm 0,51$ & $7,51 \pm 0,39$ & $2,29 \pm 0,2$ & $2,3 \pm 0,21$ & $1,06 \pm 0,06$ & $1,15 \pm 0,08$ \\
\hline 6 & $7,31 \pm 0,36$ & $7,23 \pm 0,36$ & $2,05 \pm 0,11$ & $2,30 \pm 0,17$ & $0,88 \pm 0,08$ & $1,13 \pm 0,07$ \\
\hline 8 & $7,20 \pm 0,34$ & $7,04 \pm 0,31$ & $1,84 \pm 0,1$ & $2,19 \pm 0,16$ & $0,65 \pm 0,05$ & $1,02 \pm 0,09$ \\
\hline
\end{tabular}




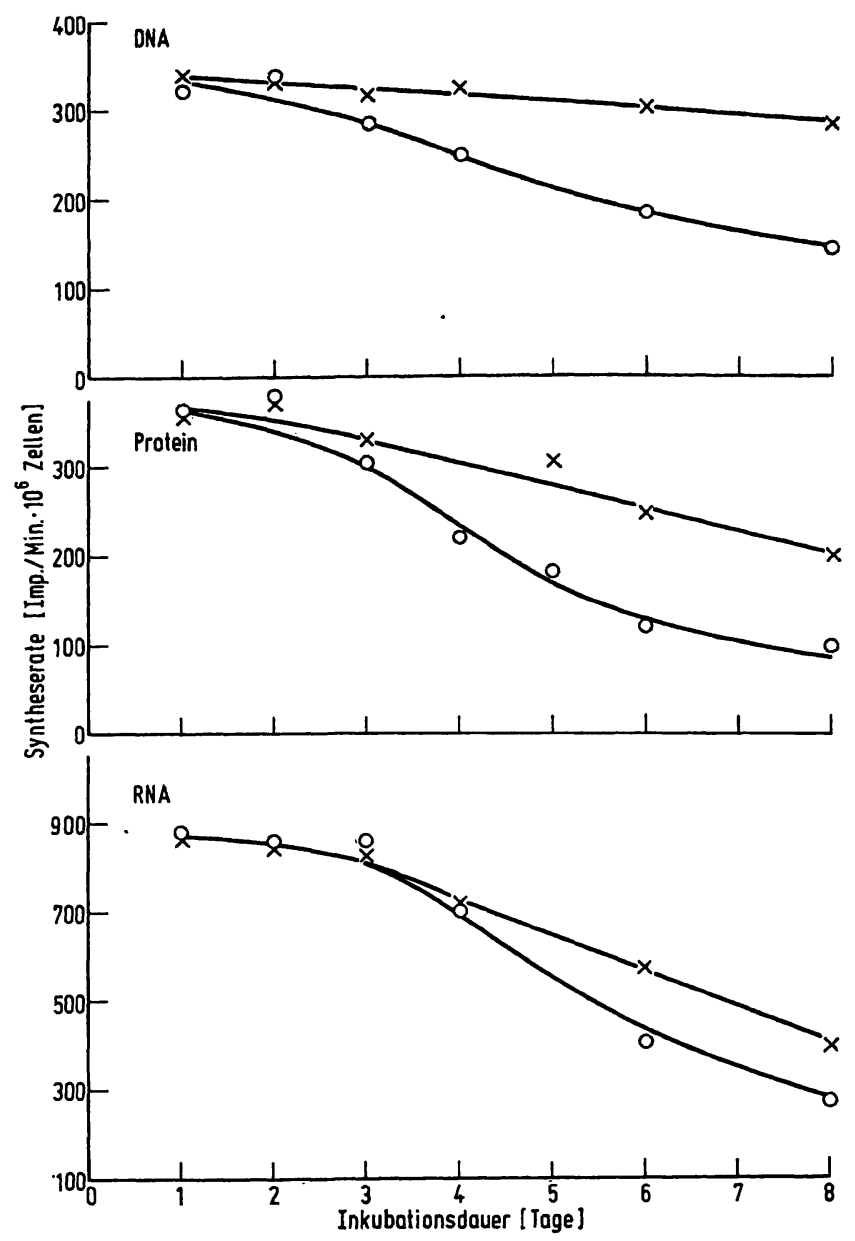

Abb. 2

Einbau von ${ }^{3} \mathrm{H}$-Thymidin, ${ }^{14} \mathrm{C}$-Leucin und ${ }^{3} \mathrm{H}$-Uridin in DNA, Protein und RNA von Yoshida-Zellen nach verschieden langem Wachstum in normalem ( $x$ ) bzw. Mg-armem (o) Medium

Der Einbau von Thymidin, Uridin und Leucin in DNA, RNA bzw. Protein ist bei den Mg-MangelKulturen nach dem 3 . Tag deutlich niedriger als bei den Kontrollen und nimmt mit zunehmender.Versuchsdauer bei den $\mathrm{Mg}$-armen Zellen wesentlich stärker ab als bei den Kontrollen (Abb. 2). Die Abnahmen sind vor allem bei den Kontrollzellen $z$. T. durch die bei beiden Zellarten gleichgroße Absterberate bedingt. Der Einbau in DNA und Protein ist am 8. Tag um $50 \%$ vermindert. Die Abnahme des UridinEinbaus in RNA ist wesentlich geringer. Das gleiche Ergebnis fand auch LuBiN (13) an Sarkomzellen, die durch Behandlung mit Amphotericin $B$ an $K$ verarmt waren.

\section{$K$-Transport}

Bei den Kontrollzellen bleibt der intrazelluläre Na-, Kund $\mathrm{Mg}$-Gehalt während des Versuchs konstant. Bei den im Mg-armen Medium wachsenden Zellen dagegen nimmt die intrazelluläre $\mathrm{K}$-Konzentration besonders nach dem 3. Tag stark ab (s. Abb. 3).

Die intrazelluläre $\mathrm{Na}$-Konzentration verhält sich reziprok. Wenn beim Abtrennen des extrazellulären $\mathrm{Na}$ und $\mathrm{K}$ durch Waschen mit $0,1 \mathrm{M} \mathrm{MgCl}_{2}$ keine Ver-

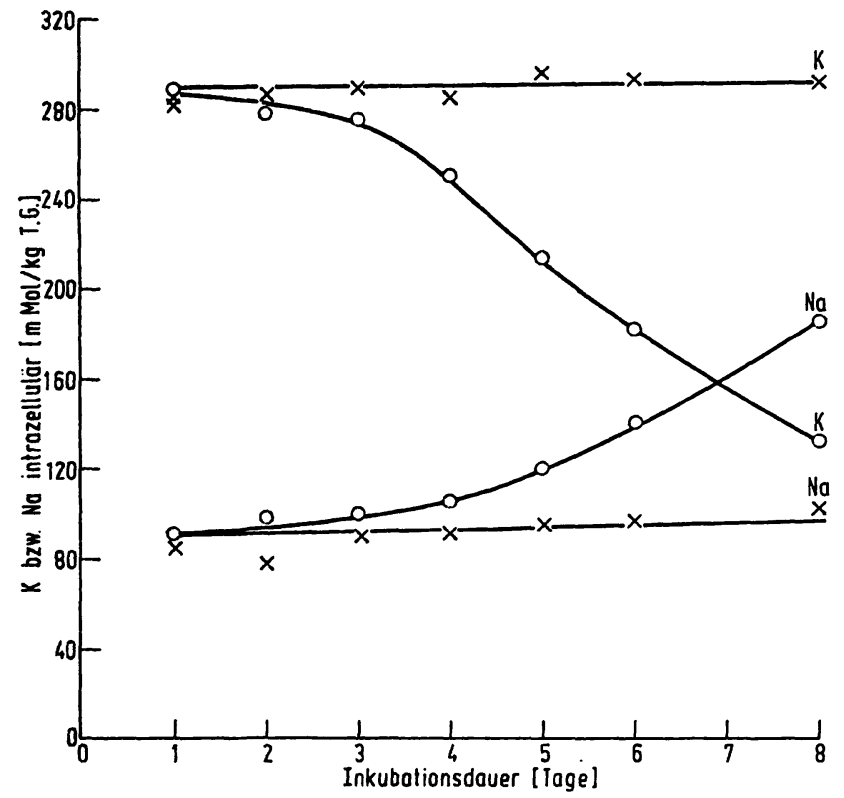

Abb. 3

Intrazellulärer Na- und K-Gehalt von Yoshida-Zellen während des Wachstums in normalem $(x)$ und Mg-armem (o) Medium, bezogen
auf Trockensubstanz (T. S.)

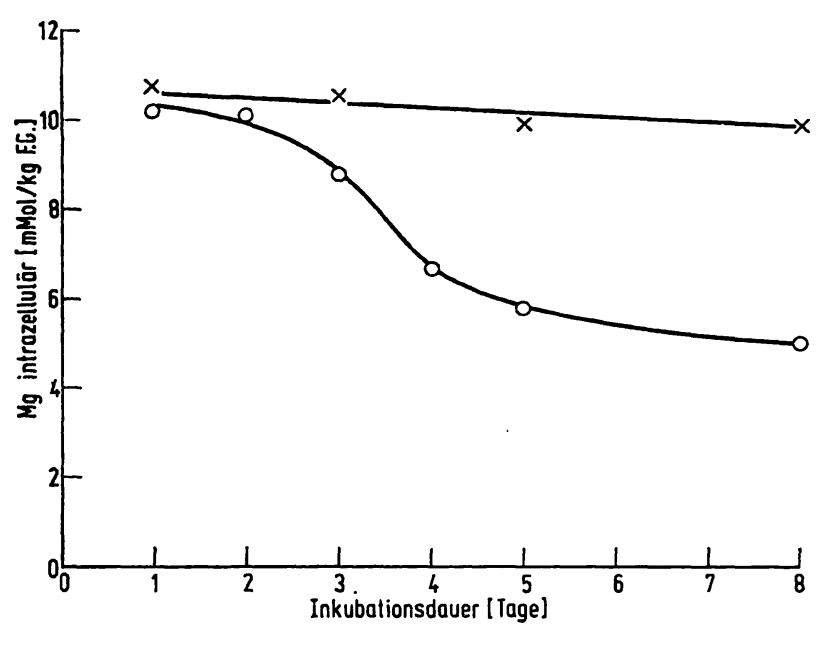

Abb. 4

Intrazellulärer $\mathrm{Mg}$-Gehalt von Yoshida-Zellen während des Wachstums in normalem $(X)$ und Mg-armem $(o)$ Medium, yezogen auf

fälschung eintritt, dann werden beim Verlust von intrazellulärem $\mathrm{K}$ jeweils $2 \mathrm{~K}$ durch $1 \mathrm{Na}$ ersetzt.

Der intrazelluläre $\mathrm{Mg}$-Gehalt nimmt dem $\mathrm{K}$-Gehalt etwa parallel ab (Abb. 4). Der Ca-Gehalt steigt dabei wie auch in anderen Geweben im Mg-Mangel $(14,15)$ an, er betrug am 8 . Tag bei den Kontrollen $1,1 \mathrm{mMol} /$ $\mathrm{kg}$ FG und $2,5 \mathrm{mMol} / \mathrm{kg}$ FG bei den Mg-MangelZellen. Als Ursache für den $\mathrm{K}$-Verlust scheidet der Stoffwechsel und ATP-Gehalt aus, da sich diese Größen nicht geändert haben.

$\mathrm{Da}$ am Na-K-Transport die Na-K-aktivierbare $\mathrm{Mg}$ abhängige ATPase der Zellmembran beteiligt ist, haben wir deren Aktivität gemessen. Tabelle 3 zeigt, $\mathrm{daB}$ sich die durch $\mathrm{Na}$ und $\mathrm{K}$ aktivierbare und die durch $\mathrm{Na}$ und $\mathrm{K}$ nicht aktivierbare Komponente der Membran-ATPase ebenfalls nicht geändert haben. $\mathrm{Da}$ die intrazelluläre $\mathrm{K}$-Konzentration im steady state die Summe aus K-Aufnahme und K-Abgabe ist, be- 
Tab. 3

ATPase-Aktivität von Yoshida-Zellen, die 8 Tage in normalem bzw ATParmen sind 20 und $40 \mathrm{Min}$. Inkubation be

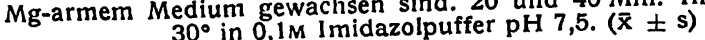

\begin{tabular}{lll}
\hline \multicolumn{1}{c}{ Zellen } & \multicolumn{2}{c}{$\mu$ Mol Phosphat/mg Protein } \\
& nach 20 Min. & nach $40 \mathrm{Min}$. \\
\hline a) Normalzellen & & \\
& & \\
Mg-ATPase & $0,42 \pm 0,030$ & $0,76 \pm 0,057$ \\
Na-K-Mg-ATPase & $0,72 \pm 0,062$ & $0,94 \pm 0,081$ \\
b) Mg-arm gewachsene & & \\
Zellen & & \\
Mg-ATPase & $0,49 \pm 0,034$ & $0,75 \pm 0,051$ \\
Na-K-Mg-ATPase & $0,69 \pm 0,041$ & $1,03 \pm 0,091$ \\
\hline
\end{tabular}

stimmten wir die Geschwindigkeit, mit der ${ }^{42} \mathrm{~K}$ aufgenommen bzw. abgegeben wird. Aus den Abbildungen 5 und 6 geht hervor, daß bei $\mathrm{Mg}$-arm gewachsenen Zellen der Austritt von ${ }^{42} \mathrm{~K}$ stark erhöht ist.

Dieser Effekt ist nicht direkt auf den geringeren $\mathrm{Mg}$ Gehalt der Mg-armen Zellen zurückzuführen, denn zur Messung der ${ }^{42} \mathrm{~K}$-Aufnahme und ${ }^{42} \mathrm{~K}$-Abgabe wurden die Zellen in Mg-reichem Medium inkubiert. Die steady state-Konzentration an $K$ normalisierte sich erst, wenn die Mg-armen Zellen in Mg-reichem Eagle-

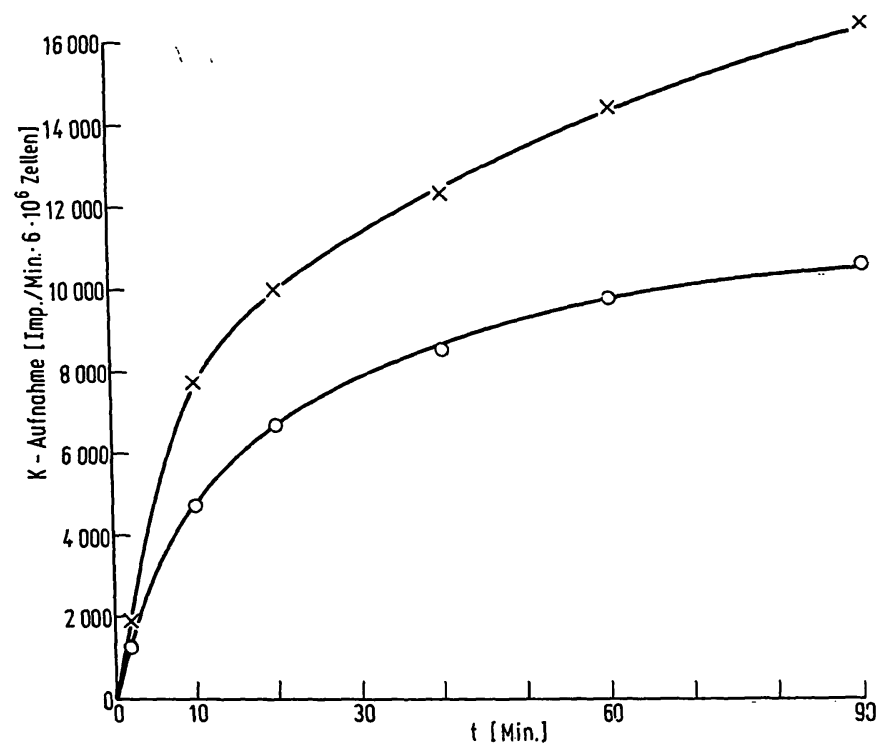

Abb. 5

"2K-Aufnahme in Yoshida-Zellen. Die Zellen waren 8 Tage in normalem ( $x$ ) bzw. Mg-armem ( $)$ Medium gewachsen und in (Mgreichem) Eagle-Medium bei $37^{\circ}$ in einer Zellkonzentration von $6 \cdot 10$ Zellen/ml inkubiert worden. Start durch Zugabe von $3 \mu \mathrm{C}=\mathrm{N} / \mathrm{ml}$ mit kalter $0,15 \mathrm{M} \mathrm{NaCl}$ gewaschen

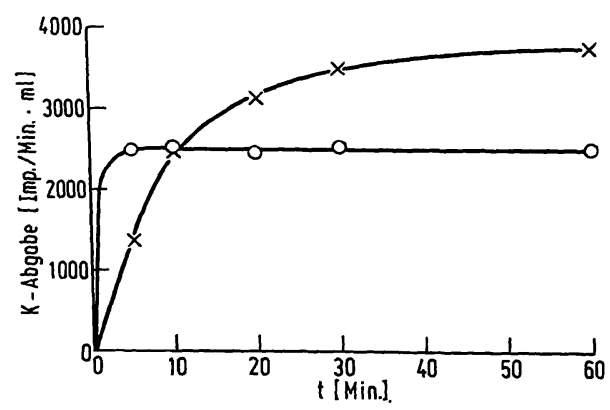

Abb. 6

${ }^{42} \mathrm{~K}$-Abgabe von Yoshida-Zellen. 8 Tage in normalem $(x)$ und $\mathrm{Mg}$ armem (o) Medium gewachsene Zellen wurden in Eagle-Medium $2 \mathrm{Stdn}$. bei $37^{\circ}$ mit $3 \mu \mathrm{C}{ }^{2} \mathrm{~K} / \mathrm{ml}$ inkubiert, einmal mit $0,15 \mathrm{M} \mathrm{NaC}$ gewaschen und in Eagle-Medium in einer Zellkonzentration von branfilter gesaugt. Aktivitätsmessung in $0,5 \mathrm{ml}$ Filtrat
Medium weitergezüchtet wurden. In derartigen Versuchen betrug der intrazelluläre $K$-Gehalt nach 8 tägigem Wachsen in $\mathrm{Mg}$-armem Medium in Übereinstimmung mit Abbildung $3118 \mathrm{mMol} / \mathrm{kg}$ Trockensubstanz. Nach 18stündigem Wachsen in normalem Eagle-Medium war der K-Gehalt auf $227 \mathrm{mMol} / \mathrm{kg}$ angestiegen.

\section{Diskussion}

Aus den Abbildungen 5 und 6 sowie aus der.Kompartmentanalyse (16) der ${ }^{42} \mathrm{~K}$-Aufnahme und der ${ }^{42} \mathrm{~K}$ Abgabe ergibt sich, daß die Geschwindigkeitskonstante für den K-Influx bei beiden Zellarten etwa gleich ist, die Geschwindigkeitskonstante für den K-Efflux ist bei den Mg-arm gewachsenen Zellen wesentlich größer. Die niedrigere steady state-Konzentration des intrazellulären $\mathrm{K}$ bei den $\mathrm{Mg}$-armen Zellen läßt sich somit auf eine vermehrte $K$-Abgabe aus den Zellen bei unverändertem aktiven Transport von $K$ in die Zellen zurückführen. Damit übereinstimmend waren auch der Energiestoffwechsel und ATP-Gehalt sowie die Energieverwertung für den aktiven Transport, die durch die Na-K-aktivierbare Membran-ATPase bewirkt wird, unverändert.

Für die vermehrte Abgabe von $K$ aus der Zelle ist wahrscheinlich das Fehlen eines Proteins verantwortlich, denn Reinkubation in Mg-reichem Medium allein führt zu keiner Normalisierung des $\mathrm{K}$-Gehalts. Diese tritt erst ein, wenn die Zellen wieder in normalem $\mathrm{Mg}$ reichem Medium gewachsen sind. Das gleiche haben wir früher bei $E$. coli gefunden (2).

$\mathrm{Da}$ die erniedrigte intrazelluläre $\mathrm{K}$-Konzentration auch an Zellen gefunden wurde, deren $\mathrm{Mg}$-Gehalt nur wenig erniedrigt war (3), und da die intrazelluläre $\mathrm{Mg}$ Ionenaktivität auch bei starker Abnahme des GesamtMg-Gehalts nahezu konstant bleibt (17), können die Abnahme der intrazellulären $\mathrm{K}$-Konzentration sowie die Änderung des Enzymmusters (4) und die bei Mg-arm ernährten Tieren selektiv verringerte, an membrangebundenen Ribosomen erfolgende Albuminsynthese (18) nicht auf eine verminderte intrazelluläre $\mathrm{Mg}$ Ionenaktivität zurückgeführt werden.

Die Abnahme der DNA und Proteinsynthese geht der Abnahme der intrazellulären K-Konzentration parallel. Es kann daraus geschlossen werden, daß die verminderte intrazelluläre K-Konzentration bzw. die Abnahme des $\mathrm{K} / \mathrm{Na}$-Quotienten in der Zelle die Synthese von DNA und Protein hemmt. Eine indirekte Wirkung infolge einer verringerten Glykolyse oder ATP-Verwertung kann - im Gegensatz zu Versuchen an $E$. coli - ausgeschlossen werden.

Mg-Mangel wäre daher neben Amphotericin B- oder Histon-Zugabe (13) ein weiteres Beispiel, daß eine verminderte intrazelluläre K-Konzentration die Synthese von Makromolekülen beeinträchtigt.

Wenn der vermehrte $\mathrm{K}$-Verlust aus der Zelle im $\mathrm{Mg}$ Mangel durch das Fehlen eines Proteins hervorgerufen wird, stellt sich die Frage nach der auslösenden Ursache. Diese ist wahrscheinlich die verminderte extrazelluläre 
Mg-Konzentration. Bei einer Abnahme des extrazellulären $\mathrm{Mg}$ werden $\mathrm{Mg}$-Komplexe der Zellmembran $\mathrm{Mg}$ abdissoziieren. Die Folgen könnten sein:

1. Von der Zellmembran kann ein Protein, das die Membran für Alkaliionen ,abdichtet", abgelöst werden. Bei der Reparation nach Wachsen in Mg-reichem Medium kann dieses neugebildete Protein durch $\mathrm{Mg}$ wieder an die Membran gebunden werden.

2. Die Zelle könnte im $\mathrm{Mg}$-armen Medium etwas $\mathrm{K}$ verlieren, so daß sekundär ein Protein, das für die Erhaltung eines hohen $\mathrm{K} / \mathrm{Na}-\mathrm{Gradienten}$ nötig ist, nicht mehr in ausreichender Menge gebildet wird. Die intrazelluläre K-Konzentration würde dadurch weiter abnehmen. Die Abnahme der Proteinsyntheserate kann nach LuBIN (13) schon durch eine geringe Abnahme der intrazellulären K-Konzentration ausgelöst werden.

Eine andere Möglichkeit, die einen vermehrten $\mathrm{K}$ Efflux erklären kann, ist die Zunahme des intrazellulären $\mathrm{Ca}_{2}$-Gehaltes bei den $\mathrm{Mg}$-Mangel-Zellen. Eine Erhöhung des intrazellulären $\mathrm{Ca}$ soll (in ungeklärter Weise) zu einer erhöhten passiven Permeabilität für $\mathrm{K}$ und in geringerem $\mathrm{MaBe}$ für $\mathrm{Na}$ führen $(19,20)$. Es wäre aber auch möglich, daß die Permeabilität für $\mathrm{Ca}$ aus dem gleichen Grunde wie für $\mathrm{K}$ und $\mathrm{Na}$ erhöht und dadurch Ca vermehrt in die Zelle diffundiert ist.

Die erwähnten Möglichkeiten brauchen einander nicht auszuschließen, sondern können kombiniert auftreten und sich ergänzen.

\section{Literatur}

1. GüNther, Th. und P. Mariss, Z. Naturforsch. 23b, 338 (1968). 2. GüNther, Th. und P. Mariss, Z. Naturforsch. 23b, 334 (1968). 3. GüNther, Th., diese Z. 8,65 (1970). - 4. GüNther, Th., diese Z. 8, 69 (1970). - 5. GüNTHER, TH. unveröffentlicht. 6. Averdunk, R. und H. Voss, Zbl. Bakteriol. I. Orig. 207, 265 (1968). - 7. Eagle, H., Science Washington 130, 432 (1959). 8. Kissmeyer-Nirson und K. E. KJerbye, Sympos. Histokomp. Test S. 381 Munksgard, Kopenhagen (1967). - 9. SregmuNd P. und H.-J. Dulce, Hoppe-Seyler's Z. physiol. Chemie 320, 149 (1960). - 10. Fiske, C. H. und Y. Subbarow, J. biol. Chemistry 66, 375 (1925). - 11. Lowry, O. H., N. Rosebrough, A. L. FarR und R. J. Randall, J. biol. Chemistry 193, 265 (1951). -
12. Liss, E., G. Palme und K. OefF, Z. Krebsforsch. 71, 89 (1968). - 13. LuBIN, M., Nature, London 213, 451 (1967). 14. MC Intyre, I. und D. Davidson, Biochem. J. 70, 456 (1958). 15. Martindale, L. und F. W. Heaton, Biochem. J. 92, 119 (1964). - 16. Arkins, G. L., Multicompartment Models for Biological Systems, S. $19 \mathrm{ff}$. Methuen and Company Ltd. London (1969). - 17. Günther, TH. und F. Dorn, Z. Naturforsch. 24b, 713 (1969). - 18. Schwartz, R., N. A. Woodcolk, J. D. Blakely, F. L. Wang und E. A. Khatrallah, J. Nutrition 100, 123 (1970). - 19. Whitrair, R., Nature, London 219, 610 (1968). 20. van Rossum, G. D. V., Nature, London 225, 638 (1970).

Prof. Dr. Th. Günther 1000 Berlin 33

Arminallee 22 